\title{
AC 2011-1167: CCLI: MODEL ELICITING ACTIVITIES: EXPERIMENTS AND MIXED METHODS TO ASSESS STUDENT LEARNING
}

\author{
Larry J. Shuman, University of Pittsburgh
}

Larry J. Shuman is Senior Associate Dean for Academics and Professor of Industrial Engineering at the University of Pittsburgh. His research focuses on improving the engineering educational experience with an emphasis on assessment of design and problem solving, and the study of the ethical behavior of engineers and engineering managers. A former senior editor of the Journal of Engineering Education, Dr. Shuman is the founding editor of Advances in Engineering Education. He has published widely in the engineering education literature, and is co-author of Engineering Ethics: Balancing Cost, Schedule and Risk - Lessons Learned from the Space Shuttle (Cambridge University Press). He received his Ph.D. from The Johns Hopkins University in Operations Research and the BSEE from the University of Cincinnati. He is an ASEE Fellow.

\section{Mary E. Besterfield-Sacre, University of Pittsburgh}

Mary Besterfield-Sacre is an Associate Professor and Fulton C. Noss Faculty Fellow in Department of Industrial Engineering, a Center Associate for the Learning Research and Development Center, and the Director for the Engineering Education Research Center at the University of Pittsburgh. Her principal research is in engineering education assessment, which has been funded by the NSF, Department of Education, Sloan Foundation, Engineering Information Foundation, and the NCIIA. Mary's current research focuses on three distinct but highly correlated areas innovative product design, entrepreneurship, and modeling. She has served as an associate editor for the JEE and is currently associate editor for the AEE Journal.

\section{Tuba Pinar Yildirim, University of Pittsburgh}

Tuba Pinar Yildirim holds a $\mathrm{PhD}$ in Industrial Engineering and is a doctoral candidate in Marketing at the Katz Graduate School of Business. She received an MS degree in Industrial Engineering at the University of Pittsburgh, and BS degrees in Industrial and Mechanical Engineering fields from Middle East Technical University in Turkey. Her interests are modeling, and cognitive and affective processes that motivate or hinder modeling skills, implementation of game theoretic and stochastic models.Her publications appeared in Journal of Marketing, Journal of Engineering Education, and International Journal of Eng. Education, IEEE Education. She was the recipient of the Industrial Engineering Best Paper Award in 2007, and was selected as a 'University of Pittsburgh Honoree' in 2008.

\section{Karen M. Bursic, University of Pittsburgh}

Karen M. Bursic is an Assistant Professor and the Undergraduate Program Director for Industrial Engineering at the University of Pittsburgh. She received her B.S., M.S., and Ph.D. degrees in Industrial Engineering from the University of Pittsburgh. Prior to joining the department she worked as a Senior Consultant for Ernst and Young and as an Industrial Engineer for General Motors Corporation. She teaches undergraduate courses in engineering economics, engineering management, and probability and statistics in Industrial Engineering as well as engineering computing in the freshman engineering program. Dr. Bursic has done research and published work in the areas of Engineering and Project Management and Engineering Education. She is a member of IIE and ASEE and is a registered Professional Engineer in the state of Pennsylvania.

\section{Natasa Vidic, University of Pittsburgh}

Assistant Professor Industrial Engineering Department Swanson School of Engineering University of Pittsburgh 


\title{
CCLI: Model Eliciting Activities: Experiments and Mixed Methods to Assess Student Learning - Part II
}

\begin{abstract}
As part of a seven university CCLI* Type 3 collaborative effort focused on models and modeling, we have extended the model eliciting activity (MEA) construct to upper division engineering programs. Originally developed and validated by mathematics education researchers, MEAs were found to have significant value as an educational tool. In particular, our overall goal has been to use this construct as a means for enhancing engineering students' problem solving and modeling skills as well as their conceptual understanding of certain engineering topics. Specifically, we have pursued two main research avenues: MEAs as teaching tools and MEAs as learning assessment tools. This paper summarizes our results for these two research thrusts as we enter our fourth project year. Particular emphasis is placed on our mixed measurements for student learning and achievement, and an examination of the relative conceptual gain for a series of MEA experiments, including those where a comparison group was available.
\end{abstract}

\section{Introduction}

“Collaborative Research: Improving Engineering Students' Learning Strategies Through Models and Modeling" is a CCLI Type 3 project involving seven university partners: California Polytechnic State University, Colorado School of Mines, Purdue University, United States Air Force Academy, University of Pittsburgh, University of Minnesota-Twin Cities and Pepperdine University. We are building upon and extending the model-eliciting activities (MEA) construct originally developed by mathematics educators that has recently been introduced into engineering education. These posed scenarios simulate authentic, real-world problems that teams of students then address. MEAs were first developed as a mechanism for observing the development of student problem-solving competencies and the growth of mathematical cognition. However, it has been increasingly documented that MEAs provide a learning methodology that helps students become better problem solvers.

We are taking the theoretical framework from mathematics education combined with research results from a series of NSF funded studies in order to create a strategic, scalable approach for addressing crucial goals in engineering education. These include:

- Developing effective, transferable competencies in problem-solving and creativity;

- More effectively learning and retaining important concepts; and

- More effectively identifying misconceptions and nurturing positive ethical frameworks.

We also are investigating and extending a suite of assessment approaches that have been developed and tested in recent MEA research. Here, our specific objectives are to:

- Expand the MEA methodology and application,

\footnotetext{
* Originally CCLI or Course, Curriculum and Laboratory Improvement Program, now Transforming Undergraduate
} Education in Science, Technology, Engineering and Mathematics or TUES 
- Study students' problem solving strategies and extend the use of MEAs to specific aspects of undergraduate reasoning and problem-solving,

- Determine solution paths first-year engineering students use in solving MEAs,

- Execute a comprehensive dissemination and infusion effort, and

- Develop a comprehensive research agenda for models and modeling in undergraduate education.

In particular, we are extending MEA implementation and complementary student and faculty assessments across our partner institutions; broadening the library of usable MEAs to different engineering disciplines; and extending the MEA approach to identifying and repairing misconceptions, using laboratory experiments as an integrated component, and introducing an ethical decision-making dimension $[1,2]$.

Our overall research goal is to enhance problem solving and modeling skills and conceptual learning of engineering students through the use of model eliciting activities. In order to accomplish this goal at the University of Pittsburgh, we are pursuing two main research routes: MEAs as teaching tools and MEA as learning assessment tools. Under the first - using MEAs as a teaching tool - we are focused on three main activities:

- Development of effective MEAs: In conjunction with our colleagues at the six partner institutions we have created a series of over 20 MEAs for upper level students that target students' problem solving skills and conceptual learning. In doing this we have found that MEAs also enhance such important professional skills as communication, teamwork, and ethical understanding.

- Implementation of (new or adapted) MEAs: focuses on implementing and assessing the developed and adapted MEAs in classroom settings as a means for studying the problem solving and modeling processes. We have introduced and rigorously assessed our MEAs in classroom settings as a means to further understand students' problem solving, modeling and teamwork processes. Assessments have included a series of comparison studies.

- Enhancing the learning benefits of MEAs: focuses on adding new conceptual dimensions to MEAs in order to enhance student learning. In particular, we are adding an "engineering ethics" dimension to the MEAs as a means of improving students' ability to recognize and resolve ethical dilemmas, and have thus created E-MEAs (ethical MEAs); we have also focused on improving conceptual understanding.

Under the second stream - using MEAs as a learning tool - we have focused on two additional activities:

- Assessing the effectiveness of MEAs in various dimensions including improving conceptual learning and problem solving: We have developed a series of assessment instruments to better understand and measure the educational benefits of using MEAs. Specifically, we are triangulating across three assessment instruments, two of which we developed: (1) pre- and post- concept inventories to assess gain, (2) an online reflection tool to assess process, and (3) a grading rubric to assess the resultant artifact (general model and specific solution). We have also developed an instrument to measure students' self-efficacy scale related to their modeling skills. 
- Assessing the MEA motivated problem solving process: Through the use of various data collection tools, including PDAs and wikis, in combination with the mentioned assessment instruments, we are identifying the various problem solving processes used by the student teams, as well as the range of problems that can be addressed, to determine how effective the various processes are relative to improved conceptual understanding.

Development of Effective MEAs - Our initial focus was to develop or adapt MEAs. The ones that we have developed are primarily designed for industrial engineering students, as well as students in engineering statistics and economics courses. These have been described in detail in two papers presented at last year's ASEE meeting [2, 3]. We have used MEAs in the classroom for three broad purposes [4]. These are:

- Integrate learning from previous courses with new information (integrator);

- Reinforce the concepts that are currently being covered (reinforcer); and

- Discover a concept that has yet to be formally introduced (discoverer).

Based on our experience, we have identified the major factors that contribute to the success of MEA implementation [4]. An important factor influencing MEA success is appropriate guidance from the instructor throughout MEA implementation. In particular, limited, corrective guidance can best ensure that students are properly focused and are addressing the targeted concept(s), especially when the solution time is constrained. Appropriate guidance tends to be positively correlated with instructor's training on MEA classroom use. If the instructor appreciates the potential benefits that the students might receive from an MEA, he/she should more readily take the extra effort to properly guide students and provide necessary feedback; otherwise the full learning benefits from the MEA exercise may not result. Part of that guidance is feedback after completion of the MEA, which plays an important role in students' understanding key concepts. Such feedback can reinforce student understanding as well as correct misconceptions. Dividing MEAs into several parts and providing feedback at points during the solution process also ensures that misconceptions are identified and corrected early allowing for student teams to redirect achieving the desired result.

As noted we have also analyzed MEAs as an assessment tool. To date, our research strongly suggests that MEAs can help educators assess their students' problem solving process. Valuable data can be obtained through the use of PDAs, Wikis, and reflection tools, as well as the actual student reports and well-designed examination questions. Currently, in order to both enhance students' problem solving processes while also assessing that process, we are requiring them to complete a reflection instrument upon completion of the MEA exercise. To do this we have modified and extended the set of Reflection Tools first proposed by Hamilton et al. [5]. As noted later in this paper, the use of reflection and reflection tools has become an important assessment methodology, allowing educators to gain insight into the team's group processes, problem solving strategies, degree of involvement, and their process for iterating among the various problem solving steps as they proceed through the exercise. Further, such information can provide engineering educators with information about the quality of student learning.

Enhancing the learning benefits of MEAs - To enhance the educational benefits of MEAs, we have focused on introducing an ethical dimension [6]. We have accomplished this by embedding 
an ethical dilemma within the MEAs that we have developed. By introducing the ethical reasoning domain, we have created what we call ethical MEAs or E-MEAs. Our objective has been to encourage students to consider how the engineering decisions that they make potentially influence the public, environment, other stakeholders, their firm and/or themselves. In addition, this also allows us to better understand the various strategies student teams use to resolve complex ethical dilemmas [6].

\section{Data Collection Tools}

We propose that MEAs can improve student learning in four specific domains: (1) conceptual understanding, (2) problem solving, (3) team work, and (4) ethical reasoning. We have been collecting data to support this assertion using seven tools:

Reflection Tools were originally suggested by Lesh, Hamilton and their colleagues. Following an MEA activity, reflection tools help students recall and then record significant aspects about what they have done (e.g., strategies used, ways the team functioned, critical points, etc.) so that the instructor might use this information to discuss with students the effectiveness of their various strategies, and types of engagement used [5]. Reflection tools enable students to better develop their conceptual frameworks for thinking about learning and problem-solving by requiring them to reflect on aspects of the exercise or process just completed.

Our reflections tool takes the form of a semi-structured instrument. We have migrated from paper to online instruments to provide ease of data collection and classification. When implemented to assess the underlying problem solving process, reflection tools provide powerful information about three major identifiers of students' problem solving process:

- Whether or not students functioned as a team or relied primarily on a single individual,

- The extent that they used an iterative problem solving approach, and

- The stages of the problem solving process the students primarily focused on.

See [2] for more details and examples.

Student Reports (artifact), i.e., the actual assigned MEA report (typically provided in memorandum format to the client), provide an artifact to assess the success of the MEA implementation. This enables us to assess the extent that the team used the targeted concepts, their level of understanding of these concepts and whether they used them correctly. Indications of how concepts are incorrectly used include:

- Inappropriate background to understand the targeted concept

- Insufficient guidance to students about expectations

- Insufficient time to fully solve the problem or students failed to allocate sufficient time and effort to properly solve the MEA

- Poorly written report; did not clearly communicate the problem and its objectives.

A successful report should clearly provide a general model for resolving the type of problem presented by the client as well as a specific solution to the given problem. If an ethical dilemma is 
embedded in the MEA, the report should also identify it and provide an appropriate resolution, in addition to pointing out other issues that might affect the recommended solution.

PDA Recordings - To analyze problem solving patterns, we have used personal digital assistants (PDA) to collect data. We do this as follows: At specific time intervals when solving the MEA students are asked to record their current task. We have programmed the PDAs so that students can record:

- The specific problem solving task being addressed,

- The perceived progress and level of effort at that point (not making progress, satisfactory, very good progress), and

- Whether the work on the task was done as a group or individually.

The PDAs are programmed to query the students every 10 minutes, at each time the student recorded the task, his/her progress and whether it was done in an individual or team setting. The number of recorded data points depended on the total time each student devoted to the project [2]. See below for more information.

Concept Inventories: we have recently turned to using concept inventories in a pre- and posttest mode as a more effective means of assessing the learning impact of a particular MEA or a set of MEAs [9]. Since most of our MEAs have revolved around statistical concepts, we have used appropriate items from the statistics concept inventory originally developed by Reed-Rhoads and colleagues [8], as well as creating our own concept inventory for Engineering Economics. By using concept inventories in this fashion we have been able to calculate effect sizes. This is especially insightful when we have a comparison group (i.e., a second section of a course that doesn't use the MEAs but covers the same material). This is discussed below.

\section{Using PDA Data to Assess the MEA Problem Solving Process}

We have investigated how students function in a team environment including: how team members iterate among the various problem solving steps and focus on particular tasks. We have also studied the relationship between process characteristics and problem solving outcomes as measured by change in thinking, grade, and ethical reasoning obtained through the use of reflective statements [7].

We have demonstrated how mobile technology tools such as personal digital assistants (PDAs) can be used for educational assessment. Specifically, we used PDAs to assess the problem solving process in when student teams addressed Model Eliciting Activities. We had each student record his or her problem solving process using a PDA and then we assessed these processes by investigating (1) teamwork, (2) how the students iterated among the problem solving steps, and (3) how they divided their time among tasks. Results suggested that process characteristics measured by PDAs and the problem solving outcomes are related. We found that higher performing students worked as a true team (as opposed to groups or individuals); had solution processes that tended to be linear (i.e., most students worked on one task at a time and did not iterate back to prior steps); and spent time on each phase of the problem solving process. 
Specifically, our results suggest that there are significant relationships between the process characteristics measured by the PDAs and the problem solving outcomes observed. We found that when students worked together in teams, they achieved higher scores on their artifacts (solutions), then if the team divided up tasks and the students essentially worked independently. To reiterate, students truly working in teams (i.e., all members working together on the problem) had a clear advantage in the outcomes of solving modeling problems compared to students who worked in groups (i.e., individuals working with some members of the team, but not all working together) or those who simply worked individually. Specifically, when their artifact was evaluated, the group solvers, on average, obtained eight less points than the team problem solvers ( $p$ value $=0.01$ ), and the individual solvers received an average of 20 points less compared to the team problem solvers $(p$-value $=0.001)$.

In addition, the data indicated that the solution process used by these student engineers is basically linear, i.e., students worked on a single task at a time and did not iterate back to a prior step once they had completed that step. This result unfortunately implies that iteration in problem solving (a desired ability) may, in fact, be an infrequent pattern among engineering students. However, it is possible that the MEAs did not require much iteration during solution.

We also investigated the time that students allocated to different phases of a model building exercise (namely, the initiation, problem solving and finishing phases). Generally speaking, we observed that allocating equal amounts of time to each problem solving phase is most beneficial. Specifically, we observed that in general, the students who earned the higher grades devoted approximately the same amount of time to each of these three phases:

- Understanding the problem and searching for a solution,

- Solving the problem, and

- Evaluating and writing up the results.

These "balanced workers" who put more emphasis on the beginning or the end phased earned 17 points more on average ( $p$-value $=0.05$ ) then students who spent most of their time on one task.

\section{Assessment of Learning Benefits - Results}

We would expect to see evidence of student learning through the use of MEAs. That is, we have hypothesized that a properly implemented MEA exercise would improve students' (1) comprehension of key engineering concepts, (2) problem solving skills, (3) ethical reasoning ability, and (4) ability to work in teams would be enhanced. One reason for this is because traditional engineering homework problems are well structured, done individually, and typically have only one correct answer. Often these "back of the chapter" problems simply require the student to repeat a procedure learned in class that applies concepts recently covered in lecture or the text. In contrast, the problems engineers are asked to solve in the workplace are the exact opposite. As Jonassen, Strobel and Lee [13] found "workplace problems are ill-structured and complex because they possess conflicting goals, multiple solution methods, non-engineering success standards, non-engineering constraints, unanticipated problems, distributed knowledge, collaborative activity systems, the importance of experience, and multiple forms of problem representation." We suggest that MEAs can be a "bridging" step to bring some of the experience of the work- 
place engineering problems into the classroom, and help students learn to apply their conceptual framework to less structured problems.

Engineering Economy Example: Two sections of an introductory engineering economy course were both taught by the same instructor. Three E-MEAs were used in a section consisting primarily of industrial engineering students (49 students). The second section consisted primarily of civil engineering and a few mechanical engineering students (70 students) [14].

The principal concern was whether the E-MEAs would contribute to an increase in learning of specific concepts (conceptual knowledge). In order to see if this was the case an engineering economy concept inventory was developed that could be used in pre and post modes. The concept inventory was designed to measure students' understanding of specific concepts that were embedded in three E-MEAs used in the course. These included: the time value of money, cost estimation, comparing alternative investments, benefit-cost ratios, use of relevant criteria, economic analysis of contemporary problems, and dealing with uncertainty. A secondary goal was to provide a measure of attainment for three of the ABET outcomes: $\mathrm{f}$ ("an understanding of professional and ethical responsibility"), h ("the broad education necessary to understand the impact of engineering solutions in a global, economic, environmental, and societal context"), and $\mathrm{j}$ ("a knowledge of contemporary issues"), all of which the E-MEAs should help reinforce [15].

The resultant Engineering Economy Concept Inventory consists of nine multiple choice and short answer questions. The instrument is administered at the start of the term (pre) and repeated at the end (post). Because two sections of the course are offered each term and taught by the same instructor, we are able to have both an experimental and comparison groups; the pre and post concept inventories were administered to both sections. All responses were graded by the same Research Assistant using the instructor developed grading key. Concurrent with developing the concept inventory, three E-MEAs were created or adapted around the same concepts. The E-MEAs were made up of two parts, an individual portion (15-20 points) and a group part (80-85 points). The individual parts consisted of three or four short answer questions aimed at encouraging the students to think about a particular decision situation comparable to what would be presented in the group part. The group part consisted of an assignment to an engineering economy team (the student group) from a fictional client to address the particular decision situation. The team was required to develop a model for solving the identified problem, apply the model to a specific case, and write a memo to a "client" that detailed the team's results and decision for the particular case. Students worked in the same three person group for all three EMEAs, which were all graded by the instructor.

Grading rubrics were developed for each to ensure consistency and to verify that students met the key requirements of: writing a quality memo to the client, outlining a logical general procedure, clearly stating assumptions, applying the appropriate economic analysis techniques, addressing the ethical issues, applying the general procedure to the client's specific case, and providing a reasonable solution. The average and standard deviation of the scores on the concept inventory for the two classes at the start and end of the term are shown in Table 1. 
Table 1: Results of Concept Inventory Scores

\begin{tabular}{|l|l|c|c|}
\cline { 3 - 4 } \multicolumn{2}{|c|}{} & $\begin{array}{c}\text { Comparison } \\
\text { Group }\end{array}$ & $\begin{array}{c}\text { Experimental } \\
\text { (E-MEA) Group }\end{array}$ \\
\hline \multirow{3}{*}{ Start of Term } & Mean & 20.38 & 17.49 \\
\cline { 2 - 4 } & Std. Dev. & 6.45 & 5.49 \\
\cline { 2 - 4 } & Sample Size & 69 & 47 \\
\hline \multirow{3}{*}{ End of Term } & Mean & 32.04 & 30.20 \\
\cline { 2 - 4 } & Std. Dev. & 5.77 & 5.26 \\
\cline { 2 - 4 } Effect Size & Sample Size & 69 & 45 \\
\hline
\end{tabular}

There is a clear statistical difference ( $p$-value from independent or paired $t \approx 0$ ) between the start and end of term mean concept inventory scores for both groups, which was not an unexpected. Further, while both effect sizes were large, the effect in the E-MEA group (experimental group) was larger than that for the comparison group. Using Cohen's $d$ with a pooled standard deviation, the effect was 1.90 and for the experimental group it was 2.36 [16].

Introductory Engineering Statistics: Three sections of an introductory statistics course were each taught by a different instructor with a different level of teaching experience during the same term. In addition to the weekly homework assignments and quizzes, three MEAs were given to the section that consisted primarily of industrial engineering students (49 students). The other two sections consisted mostly of other engineering majors (civil, chemical, computer, electrical, etc.) and had enrollments of 65 and 61 students, respectively

The primary goal of introducing MEAs was to reinforce targeted concepts covered in lecture; a second goal was to determine if students' better learned the concepts specifically targeted by MEAs compared to the traditional, comparison sections in which the MEAs were not used. Secondary goals included exposing students to open-ended, real-world problems that raised ethical questions and providing instructors with a better understanding of both students' common misconceptions and problem solving strategies. Three MEAs - Tire Reliability, Test Leads and CNC Machine [4] - were adapted and assigned to students immediately after the relevant concepts were covered in the class. These MEAs focused on Descriptive Statistics, the Central Limit Theorem and Hypothesis Testing, respectively. The MEAs consisted of an individual part (15 points) and a group part (100 points). The individual parts consisted of several questions related to the problem scenario. Its purpose was to encourage students to begin to think about aspects of the posed problem and anticipate model development. The group part consisted of an assignment to the statistics team (students) from a fictional client. Students were asked to develop a general procedure for solving this type of a problem, apply it to the specific case, and then test the given data to reach a conclusion. Again, students were required to submit their results in memo format, 
detailing the general solution procedure and explaining in detail how it was applied to the specific problem. Students were also asked to address an ethical dilemma embedded in each MEA.

In order to assess improvement in conceptual knowledge we adapted the Statistics Concept Inventory (SCI) created by Allen et al. [8]. This multiple choice assessment tool is designed for introductory statistics and consists of four categories: Descriptive, Probability, Inferential, and Graphical with nine questions in each category. Both the question and the response choices are the result of a well-designed research effort; each question includes one correct answer and several distractors, based on students' customary common sense ideas (i.e., commonly held misconceptions). Twelve questions were selected based on the specific concepts targeted by MEAs. The concept inventory was given to students at the beginning as well as the end of the semester.

Grading rubrics were developed for each of the MEAs in order to achieve consistency; the same individual graded both the individual and group part of all three MEAs. Points were assigned based on the completeness of the answers as well as the solution methodology. Similarly to Engineering Economy course, students were asked to clearly state the assumptions, apply the appropriate statistical analysis, and provide a well written memo and a reasonable solution to the problem.

The mean and standard deviation of the concept inventory scores for the beginning of the term and the end of the term are shown in Table 2. The Cohen's $d$ effect sizes for all three groups are also shown in Table 2.

Table 2: Results of Concept Inventory Scores

\begin{tabular}{|c|c|c|c|c|c|}
\hline & $\begin{array}{c}\text { Comparison } \\
\text { Group 1 }\end{array}$ & $\begin{array}{c}\text { Comparison } \\
\text { Group 2 }\end{array}$ & $\begin{array}{c}\text { Experimental } \\
\text { Group } \\
\text { Fall 2009 }\end{array}$ & $\begin{array}{c}\text { Experimental } \\
\text { Group } \\
\text { Spring 2010 }\end{array}$ \\
\hline $\begin{array}{c}\text { Start } \\
\text { Term }\end{array}$ & Mean & 4.375 & 3.919 & 4.193 & 4.77 \\
\hline & St. Dev. & 1.65 & 1.78 & 1.73 & 2.02 \\
\hline $\begin{array}{c}\text { Sample } \\
\text { Size }\end{array}$ & 65 & 61 & 49 & 48 \\
Term & $\begin{array}{c}\text { Mean } \\
\text { St. Dev. }\end{array}$ & 5.7317 & 5.877 & 6.5 & 6.17 \\
\hline & $\begin{array}{c}\text { Sample } \\
\text { Size }\end{array}$ & 41 & 2.19 & 1.79 & 2.23 \\
\hline $\begin{array}{c}\text { Effect } \\
\text { size }\end{array}$ & & $\begin{array}{c}.7786 \\
\text { Medium }\end{array}$ & $\begin{array}{c}\text { Large } \\
\text { Led }\end{array}$ & $\begin{array}{c}\text { Large } \\
\text { Medium }\end{array}$ \\
\hline
\end{tabular}

here is a significant statistical difference $(p$-value $\approx 0)$ between the start and end of term average concept inventory scores for all three groups as expected. As to the effect sizes - one comparison group had Cohen's $d$ "medium" effect size, while the other comparison group and the experimental group had "large" effect sizes. 
Examining an instructor effect: The instructor who taught the experimental group in Fall 2009 also taught one section of the same course in Spring 2010. This section consisted mostly of civil engineering majors as well as a few students from the school's other engineering departments (51 students). Two MEAs were introduced during the semester (Tire reliability and CNC machine) in a similar manner to the Fall course. The spring section also had weekly homework assignments and quizzes. The concept inventory was again administered at the beginning and at the end of semester. (Again see Table 2; Experimental Group Spring 2010).

a significant statistical difference $(p$-value $\approx .00691)$ between the pre and post average concept inventory scores as expected. However, the Cohen's $d$ effect size was lower - 0.615 (medium size). Yet, if we compare the average final scores for two sections, there is no statistical difference between the Fall 2009 and Spring 2010 ( $(p$-value $\approx .453)$ post concept inventory scores.

Impacting the Professional Skills (ABET Outcomes) - An additional result of using of MEAs is found by comparing items related to the 11 ABET outcomes on the Course Evaluation Forms. In addition to assessing the effectiveness of the instructor and the course, the evaluations contain a series of questions designed specifically to measure the students' perceptions of how well the course improved their competence in each outcome. Students used a 1 (not at all) to 5 (a great deal) scale to address the question: For each of the following [outcomes], please indicate how much this course has improved your knowledge or skill."

For the Engineering Economics study, we found that the average response to the questions related to outcomes a, d, f, g, and h was significantly higher $(\mathrm{p}<.05$, one tailed) for the experimental group (used E-MEAs) than for the comparison group (no MEAs). Further, in the Engineering Statistics study, we found additional differences (outcomes e and $\mathrm{j}$ in addition to the five above) between the one section that used MEAs and the two sections that did not. No differences were found when comparing the same instructor in probability and statistics for two different sections.

The Impact Of MEAs From The Students' Perspective - As noted, after finishing an MEA each student was asked to complete a reflection exercise (for bonus points). The Reflection Tool (RT) was used to better understand the team's solution process and student's perception of the extent that particular concepts were learned and outcomes mastered. In general, the targeted concepts were listed on the RT to prompt the students. The data suggests that students tended to identify what they had learned, but only to a certain extent. Over the series of MEAs, depending on the underlying concept, approximately 50 to $75 \%$ of the students indicated that the MEA did, in fact, help reinforce the concept; this result is confirmed by the post-concept inventory results.

\section{Determining the Cognitive Factors that Affect the Development of Modeling Ability}

A major overall goal has been to investigate the impact of cognitive factors in development of students' modeling ability $[10,11,12]$. As a result, the most in depth of our studies has been an examination of the relationship between engineering modeling skills and students' cognitive backgrounds including self-efficacy, epistemic beliefs and metacognition using model-eliciting activities (MEAs) as an assessment tool. Data were collected from sophomore students at two time periods, as well as senior level engineering students. The impact of each cognitive construct 
on change in modeling skills was measured using a growth curve model at the sophomore level, and ordinary least squares regression at the senior level.

The findings suggest that self-efficacy, through both its direct and indirect impact (as measured statistically), influences the growth of modeling abilities of an engineering student. When sophomore and senior modeling abilities are compared, the difference can be explained by varying self-efficacy levels. We found that epistemology influences modeling skill development in the following manner. Overall, the more sophisticated the student's beliefs are, the higher the level of modeling ability the student can attain, after controlling for the effects of conceptual learning, gender and the student's grade point average (GPA). This suggests that development of modeling ability may be constrained by the naiveté of one's personal epistemology. Finally, metacognition, or 'thinking about thinking,' has an impact on the development of modeling strategies of students, when the impacts of four metacognitive dimensions are considered: awareness, planning, cognitive strategy and self-checking. Students who are better at self-checking show higher growth in their modeling abilities over the course of a year, compared to students who are less proficient at self-checking. The growth in modeling abilities is also moderated by the cognitive strategy and planning skills of the student. After some experience with modeling is attained, students who have enhanced skills in these two metacognitive dimensions are observed to do better in modeling. Therefore, inherent metacognitive abilities of students can positively affect the growth of modeling ability

A result from this study is the observation that self-efficacy in engineering modeling is not well developed as students move from the sophomore to the senior level. Attempts to increase the modeling experience through the use of MEAs (e.g., having students with demonstrated modeling abilities as mentors to novice student modelers, and training them to be 'role models' for modeling) may be a way to improve self-efficacy. Further, faculty can focus developing selfefficacy in their courses, by providing more modeling practice, giving verbal encouragement to help increase self-efficacy, as well as enabling students to observe successful modeling outcomes of their peers. Reducing math anxiety levels also can be beneficial by leading to increased modeling self-efficacy, which in turn increases modeling outcomes.

\section{Discussion and Conclusions}

To date, we have developed and implemented MEAs with the aim of enhancing conceptual understanding and problem solving skills of engineering students. We have collected data from these implementations with the aim of validating such benefits. We have developed and tested a series of new MEAs in addition to adapting and implementing several developed by our colleagues. These have been implemented primarily in industrial engineering courses including a pilot engineering course that was devoted to using MEAs as a mechanism for teaching problem solving. We have introduced an ethical component into the majority of the MEAs that we developed, and have designated these as E-MEA.

Professional skills development - Further evidence of the benefits of MEA can be seen when we examine the students' solutions (artifact). Nearly all of the student teams at least identified the ethical and societal issues in the given situations and most groups specifically addressed these ethical issues and made recommendations to the client regarding how best to proceed. 
Because of the success with using E-MEAs in improving these outcomes, the instructors for experimental courses have continued to incorporate E-MEAs for the 2010-2011 academic year. Specifically, in the engineering economy course, both fall 2010 sections of the course were assigned three E-MEAs throughout the semester. Self-reported results of outcomes learned are useful in initially identifying differences in the E-MEA and non E-MEA sections of our courses, however, more substantive assessments are needed. The grading rubric used by the instructors includes points specifically given for identifying and addressing the ethical, environmental, and/or other societal issues in the group solutions to the E-MEAs. For the first two E-MEAs in the engineering economy course, only $76 \%$ of the student groups received full credit for these points. By the third E-MEA, $93 \%$ of the groups received full credit. This was consistent in both the industrial engineering section of the course as well as the section that included students in various engineering majors. Overall scores on the E-MEAs continue to show improvement in students' ability to recognize and understand the importance of the professional skill areas. Students are beginning to understand that in most cases, real problems require the decision-maker to go beyond the rational, analytical, and mathematical solutions to problems and recognize the impact of such non-quantifiable factors as safety, environmental effects, and ethical dilemmas. Increases in successful teamwork and improvement in students' communications skills (via the written memos) have also been observed. When reviewing the "reflection" data, we have also observed an increase in the percent of students that recognized and addressed the ethical issues as more E-MEAs were introduced to the same group of students.

Engineering educators today must be able to address weaknesses in achieving program outcomes. While they may have no difficulty with assessing the more traditional outcomes such as improving students skills in the application of math and science as well as experiment and design, it is the professional skills where they typically fall short. We suggest that introducing problems in the E-MEAs format can help faculty both assess and improve students' knowledge and abilities relative to the professional skills.

Further, MEAs provide an ideal method to introduce more realistic problem solving into the classroom, specifically for courses where the typical homework problems are straightforward classical textbook problems. However, implementation of MEAs in the classroom requires added effort from the instructor to select appropriate MEAs, perform additional grading, give timely feedback and engage students in productive discussions. These discussions provide a great opportunity to discuss their various solution paths, and further reinforce the concepts around which the MEA has been constructed. [14].

Based on classroom discussions and questions to the instructors, we observed significant changes in students' attitudes and openness after the last MEA in the series was completed in Engineering Statistics. In particular, reluctance and reservation toward more complex, open-ended types of problems disappeared by the end of semester. Students felt more confident about their proposed procedures and solution approaches. Overall, the MEAs provided very positive learning experience for students in the statistics course.

Relative to PDAs, that study documented how handheld technologies could be used as a process assessment tool, providing insight into problem solving characteristics of students. In our analy- 
sis, we showed that by using PDA recorded data, one can observe the problem solving process that engineering students employ during a team exercise. It provides engineering educators with an example of how PDAs can be used to collect data for analyzing process characteristics and process outcomes. As a result of using PDAs, we found that students who worked in teams and allocated relatively equal time to each phase of the scenario solution earned better grades compared to those students who focused primarily on particular phases. We suggest that this allocation of equal time to each phase may be an indicator of less task delegation and more true teamwork, a supportive finding that true teamwork is instrumental in achieving better problem solving outcomes. Hence, we have observed that mobile technologies can be beneficial in the classroom to measure, record, and evaluate educational activities, providing novel insights for the instructor about teamwork and problem solving processes. We anticipate that new avenues of research and better instructional practices will arise as handheld devices become more common in engineering education environments, and as both software and hardware improve.

\section{MEAs - Advice for Implementation}

We have noted that the use of MEAs and E-MEAs requires some effort on the part of the instructor - selecting and adapting appropriate MEAs or E-MEAs to a particular course, organizing student groups, grading, and providing rapid, appropriate feedback. However, we have found this teaching tool to be ideal for getting students to apply particular concepts to realistic, client-based problems that are generally much richer in nature than those found in a textbook. Our research strongly suggests that if used correctly, they can be effective in reinforcing and integrating course concepts as well as increasing student knowledge and understanding of various professional skills (e.g., ABET outcomes).

The two instructors who used MEAs in this study suggest the following for faculty considering using MEAs in their classroom:

1. MEAs are very useful, but require additional preparation upfront. The instructor must carefully plan how each MEA fits into the syllabus, and layout the logistical aspects of introducing MEAs. This includes due dates (individual part, group part, and reflection survey), format for turning in MEAs (electronic or paper copy; there may be both Word and Excel files), and final grade percentage must be determined upfront.

Feedback is critical. After each MEA part is completed, there must be sufficient time to grade and give feedback before moving on to the next part (or the next MEA). This is the opportunity to correct misconceptions and review common mistakes. However, it is a challenge to determine how much guidance to give to the students without leading them to a specific answer.

2. The instructor must be clear in determining the main concepts and topics that the MEA will address. As noted, MEAs can be used as either: discoverer, reinforcer or an integrator [4]. One instructor commented:

"I often use MEAs to reinforce concepts, but to some extent students must combine several main ideas from the course to be able to write up a successful solution." 
3. As discussed, MEAs offer a very good tool to enhance professional skills development, especially ABET outcomes 3.f, $\mathrm{h}$ and $\mathrm{j}$ (understanding of professional and ethical responsibility; broad education necessary to understand the impact of engineering solutions in a global, economic, environmental and societal context; knowledge of contemporary issues). An instructor stated:

"The MEAs I have used are very realistic, more so than other projects I have used in my engineering economy class. There are many MEAs that I have used, or could use so it provides me more alternatives for group projects, which sometimes feel more contrived or allowing students to pick their own project topics, which can lead to higher variability in project success."

4. The MEAs have provided a better understanding of the difficulty that students have in applying concepts learned in the class to more unstructured problems.

In addition, to improve self-efficacy and metacognition, especially as applied to modeling, we would suggest the following to interested classroom instructors:

- To improve self-efficacy, encourage students. If an instructor feels that a student is not performing at full ability, by encouraging the student to do better may help to repair low selfefficacy, which, in turn, should result in higher (modeling) learning.

- Make modeling exercises relevant; gradually increase their difficulty. To increase students' self-efficacy level, the assigned modeling tasks must match their capability, as well as their knowledge. By first introducing tasks that match students' capabilities and then gradually increasing the difficulty is should result in higher self-efficacy, while helping them become better modelers.

- Ask for multiple solution approaches. Often instructors ask students to provide a single solution. However, in the work environment engineers typically examine several alternatives. Encouraging students to consider and report on different approaches helps to build metacognition through cognitive strategy.

- Use reflective exercises. Metacognitive abilities of students can be improved by implementation of reflective statements over the course of a project. Carrying out reflections during and after the modeling exercise can help students master the planning and self-checking dimensions of metacognition.

- Introduce more real-life experiences. Students too often think in terms of short term goals, such as getting an A or graduating, rather than preparing for the long term goal of being a successful engineer. By providing real-life modeling exercises, students become better prepared and should be more motivated act like engineers. In particular, MEA-like real-life based exercises, contributes to this thinking.

- Expect more and communicate it. For example, by expecting that students to submit their solutions as if they were reports from working engineers can help reduce such thinking as 'it is just a class assignment' or 'this contributes very little to my grade' (so it is not important). This should help students to better benefit from modeling exercises. 
In summary, our collection of studies contributes to engineering education in several ways. As engineering schools focus on providing realistic learning environments for their students, improved learning and assessment tools are needed. We propose that MEAs can improve student learning. Further, we have suggested how educators might use these tools to better understand team and solution processes. For additional examples of MEAs and E-MEAs as well as guidelines for their use please see http://modelsandmodeling.net/Home.html

\section{Acknowledgement}

This research is supported in part by the National Science Foundation through DUE 071780: 'Collaborative Research: Improving Engineering Students' Learning Strategies through Models and Modeling."

\section{References}

1. L. Shuman, M. Besterfield-Sacre, Clark, R., and T.P. Yildirim (2008). The Model Eliciting Activity (MEA) Construct: Moving Engineering Research into the Classroom. Proceedings of the 9th Biennial ASME Conference on Engineering Systems Design and Analysis ESDA08, Haifa, Israel, July 7-9, 2008.

2. Shuman, L, M. Besterfield-Sacre, TP Yildirim and N. Sieworiek, "CCLI: Model Eliciting Activities: Experiments And Mixed Methods To Assess Student Learning," CD Proceedings: 2010 ASEE Annual Conference and Exposition, Louisville, KY, June 20-23, 2010.

3. Shuman, LJ, M Besterfield-Sacre, et al, Models and Modeling, Proceedings of the ASEE National Meeting, 2010.

4. Yildirim, TP, L. Shuman and M. Besterfield-Sacre, "Model Eliciting Activities: Assessing Engineering Student Problem Solving and Skill Integration Processes," International Journal of Engineering Education, 26(4), 2010, pp. 831-845.

5. Hamilton, E., Lesh, R., Lester, F., and Yoon, C., 2007, "The Use of Reflection Tools to Build Personal Models of Problem-Solving," appears in Foundations for the Future in Mathematics Education, Lesh, R., Hamilton, E., and Kaput, J. (eds.), Lawrence Erlbaum Associates, Mahwah, New Jersey, 347-365.

6. Shuman, L.J., Besterfield-Sacre, M., Yildirim, T.P. (2009) "Introducing An Ethical Component to Model Eliciting Activities, Proceedings of the ASEE Conference, June 14-17, TX, 2009.

7. Yildirim, TP, M. Besterfield-Sacre, and L. Shuman, "Use of Personal Digital Assistants in Problem Solving Process Assessment, IEEE Multidisicplinary Engineering Education, 5(3) 2010, pp 19 - 23.

8. Allen, K., A. Stone, T.R. Rhoads, and T.J. Murphy. 2004. "The Statistics Concept Inventory: Developing a Valid and Reliable Instrument." Proceedings of the 2004 American Society for Engineering Education Annual Conference and Exposition.

9. B.P. Self, R.L. Miller, A. Kean, T.J. Moore, T. Ogletree, and F. Schreiber, "Important Student Misconceptions in Mechanics and Thermal Science: Identification Using Model-Eliciting Activities", (2008). conference proceedings, Published Bibliography: Proceedings of the Frontiers in Education Conference (electronic), Saratoga Springs, New York, October 22-25, 2008.

10. Yildirim, T.P., Besterfield-Sacre, M., Shuman, L.J. (2009), “Improving Engineering Student Learning and Problem Solving Capability: Assessment of MEA Impact", Proceedings of the IERC Conference, May 30- June 2, Miami, FL, 2009.

11. Yildirim, TP, M. Besterfield-Sacre, L. Shuman, "Scale Development For Engineering Modeling Self-Efficacy," CD Proceedings: 2010 ASEE Annual Conference and Exposition, Louisville, KY, June 20-23, 2010.

12. Yildirim, TP, Understanding The Modeling Skill Shift In Engineering: The Impact Of Self-Efficacy, Epistemology, And Metacognition, unpublished PhD Dissertation, University of Pittsburgh, 2010.

13. Jonassen, D., J. Strobel and CB Lee, "Everyday Problem Solving in Engineering: Lessons for Engineering Educators," Journal of Engineering Education, 95 (2), April 2006.

14. Bursic, K. M., L.J. Shuman, M. Besterfield-Sacre, T.P. Yildirim, and N. Siewiorek. "Improving Conceptual Learning in Engineering Economy using Model Eliciting Activities (MEAs)." 2010 Industrial Engineering Research Conference, Cancun, Mexico, June 5-9, 2010. 
15. ABET, Criteria for Accrediting Engineering Programs, Baltimore: Engineering Accreditation Commission, 2010.

16. Cohen, J. (1988). Statistical Power Analysis for the Behavioral Sciences (2nd Ed.). Hillsdale, NJ: Lawrence Earlbaum Associates 